Case Report

\title{
A Case of Hyperammonemia Associated with High Dihydropyrimidine Dehydrogenase Activity
}

\author{
Keiki Nagaharu, ${ }^{1}$ Kenji Ikemura, ${ }^{2}$ Yoshiki Yamashita, ${ }^{3}$ Hiroyasu Oda, ${ }^{3}$ Mikiya Ishihara, ${ }^{3}$ \\ Yumiko Sugawara, ${ }^{3}$ Satoshi Tamaru, ${ }^{3}$ Toshiro Mizuno, ${ }^{3}$ and Naoyuki Katayama ${ }^{3}$ \\ ${ }^{1}$ Department of Hematology and Oncology, Suzuka General Hospital, Yamanohana, Yasuzuka, Suzuka, Mie Prefecture 1275-53, Japan \\ ${ }^{2}$ Department of Pharmacy, Mie University Hospital, Edobashi 2-174, Tsu, Mie Prefecture 514-8507, Japan \\ ${ }^{3}$ Department of Hematology and Oncology, Mie University Graduate School of Medicine, Edobashi 2-174, Tsu, \\ Mie Prefecture 514-8507, Japan
}

Correspondence should be addressed to Keiki Nagaharu; keiki.nagaharu@gmail.com

Received 9 October 2015; Accepted 20 December 2015

Academic Editor: Raffaele Palmirotta

Copyright (C) 2016 Keiki Nagaharu et al. This is an open access article distributed under the Creative Commons Attribution License, which permits unrestricted use, distribution, and reproduction in any medium, provided the original work is properly cited.

\begin{abstract}
Over the past decades, 5-Fluorouracil (5-FU) has been widely used to treat several types of carcinoma, including esophageal squamous cell carcinoma. In addition to its common side effects, including diarrhea, mucositis, neutropenia, and anemia, 5FU treatment has also been reported to cause hyperammonemia. However, the exact mechanism responsible for 5-FU-induced hyperammonemia remains unknown. We encountered an esophageal carcinoma patient who developed hyperammonemia when receiving 5-FU-containing chemotherapy but did not exhibit any of the other common adverse effects of 5-FU treatment. At the onset of hyperammonemia, laboratory tests revealed high dihydropyrimidine dehydrogenase (DPD) activity and rapid 5-FU clearance. Our findings suggested that 5-FU hypermetabolism may be one of the key mechanisms responsible for hyperammonemia during 5-FU treatment.
\end{abstract}

\section{Introduction}

In 1957, Heidelberger et al. reported the use of 5-FU as a new antitumoral drug [1], and at present, 5 -FU is one of the most commonly used anticancer drugs around the world. A combination of cisplatin and 5-FU is often used for first-line chemotherapy in unresectable cases of advanced esophageal carcinoma. As is the case for other anticancer drugs, the most common side effects of 5-FU, such as diarrhea, mucositis, neutropenia, and anemia, are due to its effects on the bone marrow and gastrointestinal epithelium. These common adverse effects are observed in more than half of the patients treated with 5-FU-containing regimens [2]. On the other hand, the prevalence of 5-FU-induced hyperammonemia has been reported to range within $5.7 \%-$ $7.0 \%$ [3-5]. The exact mechanism responsible for 5-FUinduced hyperammonemia remains unknown. Herein, we report a patient who developed recurrent hyperammonemia.

\section{Case Report}

A 60-year-old man presented with a 1-month history of progressively worsening discomfort during swallowing. His medical history included treated gastric cancer (5 years earlier) and emphysema. The patient reported that he had smoked approximately 20 cigarettes per day since the age of 20. Laboratory tests did not detect hepatic disorders or renal problems. Upper gastrointestinal endoscopy revealed an ulcerative lesion with elevated distinct borders in the lower esophagus, and endoscopic ultrasound detected serosal invasion. The lesion was diagnosed as a squamous cell carcinoma from a biopsy. A positron emission tomography (PET) examination confirmed lung metastasis. As a result, the patient was clinically staged as CT3N1M1 and was treated with 5-FU and cisplatin. However, his obstructive swallowing problems continued to worsen. We next administered concurrent radiotherapy as a palliative treatment. The treatment regimen (FP regimen) consisted of 5-FU at a dose of 
TABLE 1: Laboratory findings.

\begin{tabular}{|c|c|c|c|}
\hline & Day of onset & The following day & [Normal range] \\
\hline \multicolumn{4}{|l|}{ [Peripheral blood] } \\
\hline WBC & $8080 / \mu \mathrm{L}$ & $5180 / \mu \mathrm{L}$ & $3500-9000 / \mu \mathrm{L}$ \\
\hline $\mathrm{RBC}$ & $382 \times 10^{4} / \mu \mathrm{L}$ & $414 \times 10^{4} / \mu \mathrm{L}$ & $376-500 \times 10^{4} / \mu \mathrm{L}$ \\
\hline $\mathrm{Hb}$ & $15.3 \mathrm{~g} / \mathrm{dL}$ & $12.9 \mathrm{~g} / \mathrm{dL}$ & $11.3-15.2 \mathrm{~g} / \mathrm{dL}$ \\
\hline $\mathrm{Ht}$ & $33.3 \%$ & $37.0 \%$ & $33.4-44.9 \%$ \\
\hline $\mathrm{MCV}$ & $87.2 \mathrm{fL}$ & $89.4 \mathrm{fL}$ & $82.7-101 \mathrm{fL}$ \\
\hline Plt & $26.3 \times 10^{4} / \mu \mathrm{L}$ & $25.6 \times 10^{4} / \mu \mathrm{L}$ & $13.0-36.9 \times 10^{4} / \mu \mathrm{L}$ \\
\hline \multicolumn{4}{|l|}{ [Coagulation test] } \\
\hline APTT & $31.0 \mathrm{sec}$ & & $25.0-45.0 \mathrm{sec}$ \\
\hline $\mathrm{PT}$ & $14.2 \mathrm{sec}$ & & $13.5-15.0 \mathrm{sec}$ \\
\hline D-dimer & $0.66 \mu \mathrm{g} / \mathrm{mL}$ & & $<0.50 \mu \mathrm{g} / \mathrm{mL}$ \\
\hline \multicolumn{4}{|l|}{ [Biochemistry] } \\
\hline $\mathrm{TP}$ & $6.2 \mathrm{~g} / \mathrm{dL}$ & $5.6 \mathrm{~g} / \mathrm{dL}$ & $6.5-8.5 \mathrm{~g} / \mathrm{dL}$ \\
\hline Alb & $3.4 \mathrm{~g} / \mathrm{dL}$ & $3.4 \mathrm{~g} / \mathrm{dL}$ & $4.1-5.3 \mathrm{~g} / \mathrm{dL}$ \\
\hline AST & $20 \mathrm{IU} / \mathrm{L}$ & $20 \mathrm{IU} / \mathrm{L}$ & 10-35 IU/L \\
\hline ALT & $25 \mathrm{IU} / \mathrm{L}$ & $23 \mathrm{IU} / \mathrm{L}$ & 10-35 IU/L \\
\hline $\mathrm{LDH}$ & $182 \mathrm{IU} / \mathrm{L}$ & $155 \mathrm{IU} / \mathrm{L}$ & 110-225 IU/L \\
\hline$\gamma$-GTP & & $50 \mathrm{IU} / \mathrm{L}$ & $8-60 \mathrm{IU} / \mathrm{L}$ \\
\hline T-Bil & $0.6 \mathrm{mg} / \mathrm{dL}$ & $0.60 \mathrm{mg} / \mathrm{dL}$ & $0.2-1.3 \mathrm{mg} / \mathrm{dL}$ \\
\hline Glu & $101 \mathrm{mg} / \mathrm{dL}$ & & $80-120 \mathrm{mg} / \mathrm{dL}$ \\
\hline BUN & $34 \mathrm{mg} / \mathrm{dL}$ & $31 \mathrm{mg} / \mathrm{dL}$ & $9.6-22.0 \mathrm{mg} / \mathrm{dL}$ \\
\hline Cre & $0.95 \mathrm{mg} / \mathrm{dL}$ & $1.09 \mathrm{mg} / \mathrm{dL}$ & $<1.20 \mathrm{mg} / \mathrm{dL}$ \\
\hline $\mathrm{Na}$ & $129 \mathrm{mEq} / \mathrm{L}$ & $136 \mathrm{mEq} / \mathrm{L}$ & $138-145 \mathrm{mEq} / \mathrm{L}$ \\
\hline $\mathrm{K}$ & $2.6 \mathrm{mEq} / \mathrm{L}$ & $3.1 \mathrm{mEq} / \mathrm{L}$ & $3.4-4.7 \mathrm{mEq} / \mathrm{L}$ \\
\hline $\mathrm{Cl}$ & $93 \mathrm{mEq} / \mathrm{L}$ & $97 \mathrm{mEq} / \mathrm{L}$ & 99-108 mEq/L \\
\hline CRP & $0.47 \mathrm{mg} / \mathrm{dL}$ & $0.44 \mathrm{mg} / \mathrm{dL}$ & $<0.30 \mathrm{mg} / \mathrm{dL}$ \\
\hline $\mathrm{NH}^{3}$ & $131 \mu \mathrm{g} / \mathrm{dL}$ & $44 \mu \mathrm{g} / \mathrm{dL}$ & $<18 \mu \mathrm{g} / \mathrm{dL}$ \\
\hline 5-FU concentration & $13 \mathrm{ng} / \mathrm{mL}$ & $<10 \mathrm{ng} / \mathrm{mL}$ & $600 \mathrm{ng} / \mathrm{mL}$ (steady state) \\
\hline
\end{tabular}

Laboratory findings revealed hyperammonemia and mild hyponatremia. Serum concentration of 5-FU was low.

$800 \mathrm{mg} / \mathrm{m}^{2}$ on days $1-5$ and cisplatin at a dose of $80 \mathrm{mg} / \mathrm{m}^{2}$ on day 1 and was repeated every 28 days. The patient did not exhibit specific adverse effects during the first course of treatment. After the completion of that, a second course of the same regimen was started. However, the patient fell unconscious 72 hours after the initiation of treatment.

On physical examination, he was unconscious (Glasgow Coma Scale: E1V3M5) and afebrile and had a pulse rate of $69 \mathrm{bpm}$ and a blood pressure of $111 / 61 \mathrm{mmHg}$. There were no signs of mucositis. A neurological examination did not detect paralysis or abnormal reflexes. The patient's laboratory data revealed hyperammonemia, mild hyponatremia, and a high blood urea nitrogen (BUN) level. Other findings are shown in Table 1. Radiological assessments including computed tomography (CT) and magnetic resonance imaging (MRI) scans of the patient's head did not detect any apparent cause of the patient's condition. On the following day, his condition normalized with only normal saline hydration, and he did not exhibit sequelae. We subsequently diagnosed the patient with 5-FU-related hyperammonemia.
TABLE 2: Urinary analysis of dihydrouracil and uracil.

\begin{tabular}{lccc}
\hline & Dihydrouracil & Uracil & Ratio \\
\hline Patient's value & $5.325 \mu \mathrm{g} / \mathrm{mL}$ & $0.495 \mu \mathrm{g} / \mathrm{mL}$ & 10.75 \\
Normal range [6] & $1.7-13.1 \mu \mathrm{g} / \mathrm{mL}$ & $4-30 \mu \mathrm{g} / \mathrm{mL}$ & $0.3-0.77$ \\
\hline
\end{tabular}

Urinary DHU/U was much higher than normal. These findings supported the high activity of dihydropyrimidine dehydrogenase.

At the onset of hyperammonemia, the patient's serum 5 -FU concentration during the unconscious state was significantly lower $(13 \mathrm{ng} / \mathrm{mL})$ than the normal range $(500-$ $600 \mathrm{ng} / \mathrm{mL}$ ). In 5-FU metabolism, approximately $80 \%$ of infused $5-\mathrm{FU}$ is degraded by $\mathrm{DPD}$, the initial and ratelimiting enzyme in the catabolism of pyrimidine bases, and this process produces ammonia as the end product. Due to the rapid clearance of 5-FU, we evaluated the patient's DPD activity using the urinary dihydrouracil to uracil ratio (DHU/U). Table 2 shows the patient's DPD activity and a high $\mathrm{DHU} / \mathrm{U}$ ratio, which indicated that his 5-FU metabolism had not been suppressed. 
We concluded that continuing with the FP regimen would be harmful to the patient. He was subsequently treated with taxane-based treatment, which resulted in PD. He died approximately six months after being diagnosed due to cancer progression.

\section{Discussion}

Our patient developed hyperammonemia without other adverse effects. Laboratory examination revealed a high $\mathrm{DHU} / \mathrm{U}$ ratio. Although urinary $\mathrm{DHU} / \mathrm{U}$ is an indirect method to assess DPD activity, his high DPD activity was supported by his undetectably low serum 5-FU concentration and the absence of most of the common adverse effects of 5-FU treatment (including diarrhea, mucositis, neutropenia, and anemia). These findings suggested that rapid metabolism of 5-FU may cause faster than normal accumulation of ammonia.

Previous studies have investigated the relationship between DPD activity and 5-FU toxicity [7-11]. Clinically severe 5-FU toxicity was reported in a family with DPD deficiency [12]. Moreover, relatively low DPD activity was reported to be a risk factor for severe cytotoxic adverse effects [7]. On the other hand, Kim et al. described a case of hyperammonemia with high DPD synthesis, similar to our case [13]. Although the etiology for acquisition of high DPD is unknown, Li et al. demonstrated that exposure to 5-FU causes resistance to 5-FU, with upregulation of DPD activity, using a human colorectal carcinoma xenograft nude mouse model [14]. In the present and previous cases, the first administration of 5-FU may have induced upregulation of DPD activity.

There are some limitations in our hypothesis. First, we were unable to assess the actual DPD activity in the liver tissue. Because it was reported that hepatic DPD activity is correlated with the urinary $\mathrm{DHU} / \mathrm{U}$ ratio, we indirectly analyzed the patient's DPD activity using the urinary DHU/U ratio, as was performed in a previous study [6]. Although urine and salivary $\mathrm{DHU} / \mathrm{U}$ ratios were reported to be good predictors of the adverse effect of 5-FU [7, 15], further investigation is required to establish a method for precise DPD evaluation. Second, the DPD activity before treatment was not evaluated. Thus, we were unable to identify whether the high DPD of our case was congenital or acquired. As mentioned above, the absence of hyperammonemia during his first course suggested acquired high DPD. However, previous reports also performed the same regimen without incidence of hyperammonemia [13]. This suggests that other factors may be required for development of hyperammonemia. Third, we did not evaluate genetic analysis of DPD and other enzymes in our case. Kim et al. reported genetic mutations of thymidylate synthetase which is the main target enzyme of 5-FU in their hyperammonemia cases [16]. Not only catabolic enzymes but also the target of 5-FU may play a role in hyperammonemia.

In conclusion, the present case suggested that high DPD activity may be a trigger of hyperammonemia. While this report suggested a possible mechanism for such hyperammonemia, the exact mechanism remains unknown, and further investigation on the association between hyperammonemia and DPD activity is warranted.

\section{Abbreviation}

5-FU: 5-Fluorouracil

DPD: Dihydropyrimidine dehydrogenase

CT: $\quad$ Computed tomography

BUN: Blood urea nitrogen

MRI: $\quad$ Magnetic resonance imaging

DHU/U: Dihydrouracil to uracil ratio.

\section{Conflict of Interests}

The authors declare that they have no competing interests.

\section{Authors' Contribution}

Keiki Nagaharu participated in the treatment of the patient in this case report and drafted the paper. Kenji Ikemura assisted in the examination of catabolites. Yoshiki Yamashita participated in the treatment of the patient. Hiroyasu Oda, Mikiya Ishihara, Yumiko Sugawara, and Satoshi Tamaru participated in the planning of treatment. Toshiro Mizuno and Naoyuki Katayama supervised and assisted in drafting the paper. All authors read and approved the final paper.

\section{Acknowledgment}

The authors thank their patient's family for allowing them to write about the case for the benefit of the future patients.

\section{References}

[1] C. Heidelberger, N. K. Chaudhuri, P. Danneberg et al., "Fluorinated pyrimidines, a new class of tumour-inhibitory compounds," Nature, vol. 179, no. 4561, pp. 663-666, 1957.

[2] K. Tsuji, H. Yasui, Y. Onozawa et al., "Modified folfox-6 therapy for heavily pretreated advanced gastric cancer refractory to fluorouracil, irinotecan, cisplatin and taxanes: a retrospective study," Japanese Journal of Clinical Oncology, vol. 42, no. 8, pp. 686-690, 2012.

[3] C.-C. Liaw, S.-J. Liaw, C.-H. Wang, M.-C. Chiu, and J.-S. Huang, "Transient hyperammonemia related to chemotherapy with continuous infusion of high-dose 5-fluorouracil," Anti-Cancer Drugs, vol. 4, no. 3, pp. 311-315, 1993.

[4] K. H. Yeh and A. L. Cheng, "High-dose 5-fluorouracil infusional therapy is associated with hyperammonaemia, lactic acidosis and encephalopathy," British Journal of Cancer, vol. 75, no. 3, pp. 464-465, 1997.

[5] M. Nobuhiro, G. Takashi, M. Takanori et al., "Risk factors for hyperammonemia during mFOLFOX6 treatment," Gan To Kagaku Ryoho, vol. 40, no. 4, pp. 483-487, 2013.

[6] R. W. Sparidans, T. M. Bosch, M. Jörger, J. H. M. Schellens, and J. H. Beijnen, "Liquid chromatography-tandem mass spectrometric assay for the analysis of uracil, 5,6-dihydrouracil and $\beta$-ureidopropionic acid in urine for the measurement of 
the activities of the pyrimidine catabolic enzymes," Journal of Chromatography B: Analytical Technologies in the Biomedical and Life Sciences, vol. 839, no. 1-2, pp. 45-53, 2006.

[7] A. B. P. van Kuilenburg, J. Haasjes, D. J. Richel et al., "Clinical implications of dihydropyrimidine dehydrogenase (DPD) deficiency in patients with severe 5-fluorouracil-associated toxicity: identification of new mutations in the DPD gene," Clinical Cancer Research, vol. 6, no. 12, pp. 4705-4712, 2000.

[8] Y. Wettergren, G. Carlsson, E. Odin, and B. Gustavsson, "Pretherapeutic uracil and dihydrouracil levels of colorectal cancer patients are associated with sex and toxic side effects during adjuvant 5-fluorouracil-based chemotherapy," Cancer, vol. 118, no. 11, pp. 2935-2943, 2012.

[9] M. Gamelin, M. Boisdron-Celle, V. Guérin-Meyer et al., "Correlation between uracil and dihydrouracil plasma ratio, fluorouracil (5-FU) pharmacokinetic parameters, and tolerance in patients with advanced colorectal cancer: a potential interest for predicting 5-FU toxicity and determining optimal 5-FU dosage," Journal of Clinical Oncology, vol. 17, no. 4, pp. 1105-1110, 1999.

[10] Y. Nakayama, K. Matsumoto, Y. Inoue et al., "Correlation between the urinary dihydrouracil-uracil ratio and the 5-FU plasma concentration in patients treated with oral 5-FU analogs," Anticancer Research, vol. 26, no. 5, pp. 3983-3988, 2006.

[11] M. H. Kristensen, P. Pedersen, and J. Mejer, "The value of dihydrouracil/uracil plasma ratios in predicting 5-fluorouracilrelated toxicity in colorectal cancer patients," Journal of International Medical Research, vol. 38, no. 4, pp. 1313-1323, 2010.

[12] B. E. Harris, J. T. Carpenter, and R. B. Diasio, "Severe 5fluorouracil toxicity secondary to dihydropyrimidine dehydrogenase deficiency. A potentially more common pharmacogenetic syndrome," Cancer, vol. 68, no. 3, pp. 499-501, 1991.

[13] Y.-A. Kim, H. C. Chung, H. J. Choi, S. Y. Rha, J. S. Seong, and H.-C. Jeung, "Intermediate dose 5-fluorouracil-induced encephalopathy," Japanese Journal of Clinical Oncology, vol. 36, no. 1, pp. 55-59, 2006.

[14] L.-H. Li, H. Dong, F. Zhao et al., "The upregulation of dihydropyrimidine dehydrogenase in liver is involved in acquired resistance to 5-fluorouracil," European Journal of Cancer, vol. 49, no. 7, pp. 1752-1760, 2013.

[15] G. Carlsson, E. Odin, B. Gustavsson, and Y. Wettergren, "Pretherapeutic uracil and dihydrouracil levels in saliva of colorectal cancer patients are associated with toxicity during adjuvant 5-fluorouracil-based chemotherapy," Cancer Chemotherapy and Pharmacology, vol. 74, no. 4, pp. 757-763, 2014.

[16] S.-R. Kim, C.-H. Park, S. Park, J.-O. Park, J. Lee, and S.-Y. Lee, "Genetic polymorphisms associated with 5-fluorouracilinduced neurotoxicity," Chemotherapy, vol. 56, no. 4, pp. 313317, 2010. 


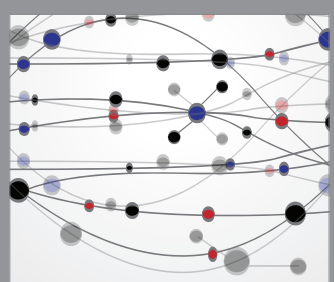

The Scientific World Journal
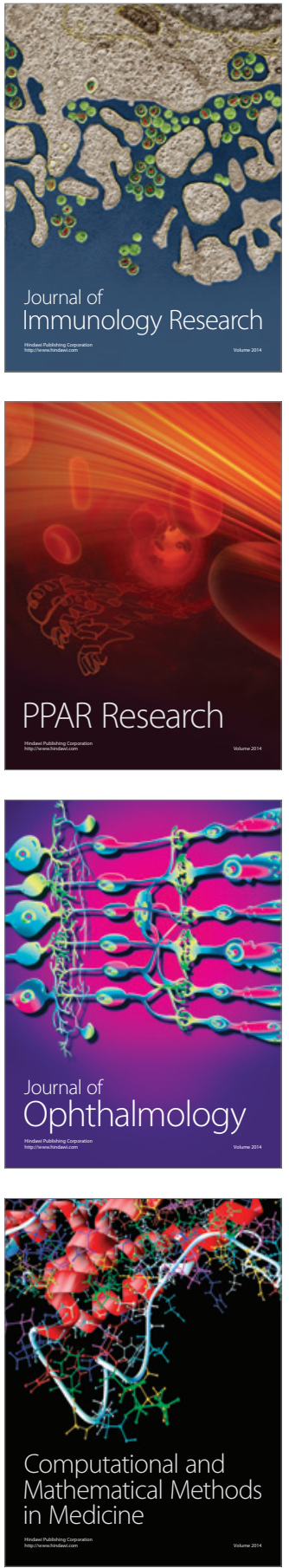



Gastroenterology Research and Practice

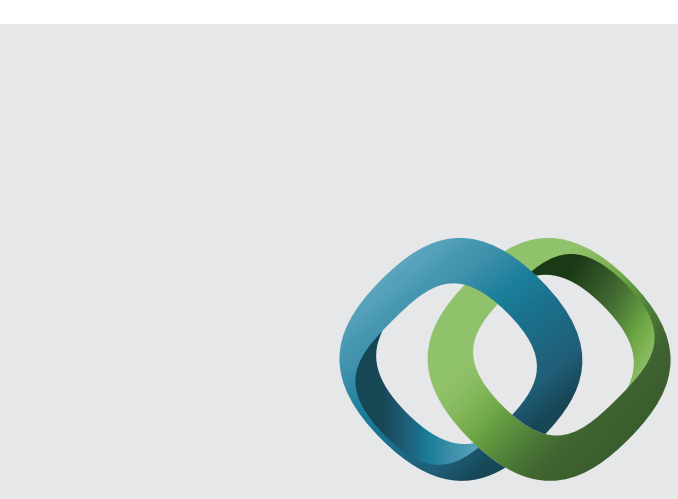

\section{Hindawi}

Submit your manuscripts at

http://www.hindawi.com
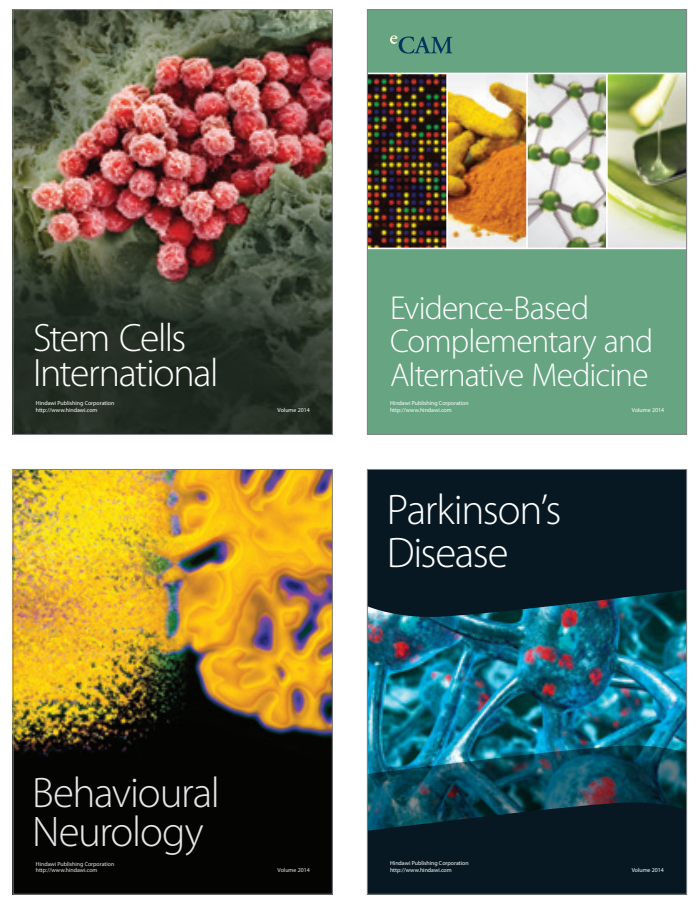
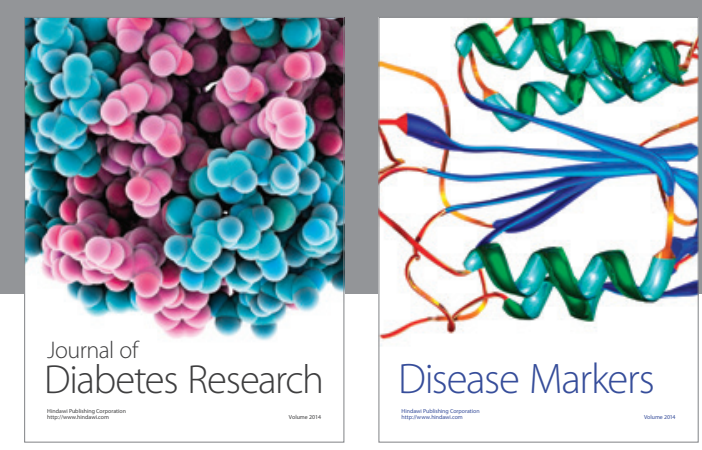

Disease Markers
